\title{
Robotic and robot-assisted skull base neurosurgery: systematic review of current applications and future directions
}

\author{
Dhiraj J. Pangal, BS, ${ }^{1}$ David J. Cote, MD, PhD, ${ }^{1}$ Jacob Ruzevick, MD, ${ }^{1}$ Benjamin Yarovinsky, \\ Guillaume Kugener, MEng, ${ }^{1}$ Bozena Wrobel, MD, ${ }^{2}$ Elisabeth H. Ference, MD, MPH, ${ }^{2}$ \\ Mark Swanson, MD, ${ }^{2}$ Andrew J. Hung, MD, ${ }^{3}$ Daniel A. Donoho, MD, ${ }^{4}$ Steven Giannotta, MD, ${ }^{1}$ \\ and Gabriel Zada, MD, MS'1
}

\begin{abstract}
1 USC Brain Tumor Center, Department of Neurosurgery, Keck School of Medicine of the University of Southern California, LoS Angeles; ${ }^{2}$ USC Caruso Department of Otolaryngology, Keck School of Medicine of the University of Southern California, Los Angeles; ${ }^{3}$ USC Institute of Urology, Keck School of Medicine of the University of Southern California, Los Angeles, California; and ${ }^{4}$ Division of Neurosurgery, Center for Neuroscience, Children's National Medical Center, Washington, DC
\end{abstract}

OBJECTIVE The utility of robotic instrumentation is expanding in neurosurgery. Despite this, successful examples of robotic implementation for endoscopic endonasal or skull base neurosurgery remain limited. Therefore, the authors performed a systematic review of the literature to identify all articles that used robotic systems to access the sella or anterior, middle, or posterior cranial fossae.

METHODS A systematic review of MEDLINE and PubMed in accordance with PRISMA guidelines performed for articles published between January 1, 1990, and August 1, 2021, was conducted to identify all robotic systems (autonomous, semiautonomous, or surgeon-controlled) used for skull base neurosurgical procedures. Cadaveric and human clinical studies were included. Studies with exclusively otorhinolaryngological applications or using robotic microscopes were excluded.

RESULTS A total of 561 studies were identified from the initial search, of which 22 were included following full-text review. Transoral robotic surgery (TORS) using the da Vinci Surgical System was the most widely reported system (4 studies) utilized for skull base and pituitary fossa procedures; additionally, it has been reported for resection of sellar masses in 4 patients. Seven cadaveric studies used the da Vinci Surgical System to access the skull base using alternative, non-TORS approaches (e.g., transnasal, transmaxillary, and supraorbital). Five cadaveric studies investigated alternative systems to access the skull base. Six studies investigated the use of robotic endoscope holders. Advantages to robotic applications in skull base neurosurgery included improved lighting and 3D visualization, replication of more traditional gesture-based movements, and the ability for dexterous movements ordinarily constrained by small operative corridors. Limitations included the size and angulation capacity of the robot, lack of drilling components preventing fully robotic procedures, and cost. Robotic endoscope holders may have been particularly advantageous when the use of a surgical assistant or second surgeon was limited.

CONCLUSIONS Robotic skull base neurosurgery has been growing in popularity and feasibility, but significant limitations remain. While robotic systems seem to have allowed for greater maneuverability and 3D visualization, their size and lack of neurosurgery-specific tools have continued to prevent widespread adoption into current practice. The next generation of robotic technologies should prioritize overcoming these limitations.

https://thejns.org/doi/abs/10.3171/2021.10.FOCUS21505

KEYWORDS robot-assisted surgery; skull base; pituitary; endoscopic; endonasal

$\mathrm{T}$ HE endoscopic endonasal approach (EEA) has grown in popularity as the standard surgical approach for pathologies of the midline skull base..$^{1-3}$ Benefits of the EEA include a minimally invasive technique, superior visualization, and improved access to the parasellar regions compared with traditional microscopic endonasal and transbasal approaches. Despite the advantages of the EEA, limitations of this technique include a 2D field of view, constrained operative corridors, the need for an assistant or second surgeon (four-handed approach),

ABBREVIATIONS EEA = endoscopic endonasal approach; TORS = transoral robotic surgery; VR = virtual reality.

SUBMITTED August 24, 2021. ACCEPTED October 22, 2021.

INCLUDE WHEN CITING DOI: 10.3171/2021.10.FOCUS21505. 
and a significant learning curve for mastering the endoscopic technique. ${ }^{4,5}$

The use of robotic systems offers a potential solution for many of these limitations, while potentially improving patient outcomes. While the use of robotics has been increasingly applied in other surgical subspecialties, including urology, general surgery, gynecology, and instrumented spine surgery, the use of robotics to access pathology associated with the skull base has been limited due to the related small operative corridors and perilous anatomy. ${ }^{6,7}$

There is significant literature pertaining to the use of robot-assisted surgery for accessing the skull base for otolaryngological applications, including relatively large clinical case series and systematic reviews. ${ }^{8-10}$ Given the growing use of the EEA to reach the skull base and the continually reduced size of robot-assisted systems such as the da Vinci Surgical System (Intuitive Surgical Inc.), robotic applications in skull base neurosurgery are growing in importance but remain relatively understudied.

To accurately characterize the current utility and future directions of robotics within skull base neurosurgery, we conducted a systematic review of the literature to identify all articles that used robotic systems to access the sella or anterior, middle, or posterior cranial fossae. We additionally describe future directions of robotics for skull base pathology and discuss systems and approaches which may become available in the future.

\section{Methods}

The Preferred Reporting Items for Systematic Reviews and Meta-Analyses (PRISMA) guidelines were used. ${ }^{11} \mathrm{We}$ searched MEDLINE and PubMed for articles published between January 1, 1990, and August 1, 2021, using the following search criteria: (((robotics) OR (robotic surgery) OR (TORS)) AND ((pituitary) OR (adenoma) OR (skull Base) OR (sella))).

\section{Inclusion and Exclusion Criteria}

Studies were included if they were published in the English language; used autonomous, semiautonomous, or operator-controlled robotic instrumentation; accessed skull base anatomy, including the sella turcica, anterior, middle, or posterior cranial fossae; were performed in patients or cadavers; and identified neurological surgeons as surgical operators.

Studies were excluded if they were review articles, investigated the use of robotics in radiosurgery, focused on surgical simulation or planning, incorporated exclusively virtual reality (VR) robotic technology, or focused exclusively on robotic visualization using external cameras (e.g., exoscopes). Robotic endoscope holders were considered distinct from robotic external cameras and, thus, were included. Studies were also excluded if they investigated solely otorhinolaryngological surgical techniques (e.g., thyroidectomy, oropharynx [tonsil, base of tongue], submandibular gland access, and infratemporal fossa dissection), or if they were performed exclusively on phantoms (e.g., a dry skull with VR/computer-simulated results).

Two independent reviewers screened titles and abstracts for relevance. Following full-text review, a third author arbitrated the two lists to include the 22 studies contained within the analysis. A PRISMA flow diagram is shown in Fig. 1.

\section{Results}

A total of 561 studies were identified after the initial search and removal of duplicates. Of these, 42 remained after the initial screening of titles and abstracts. Of these, 22 articles were included in the final analysis following full-text review. Articles were excluded for the following reasons: no results obtained in cadavers or patients (e.g., phantoms and purely technical descriptions; $n=7$ ), not performed by neurosurgeons or in relation to neurosurgical pathology $(n=9)$, non-English-language studies $(n=$ $2)$, review article $(n=1)$, and robotic microscope study only $(\mathrm{n}=1)$.

Studies were divided into the following categories: transoral robotic skull base surgery (TORS), alternative approaches to the skull base, alternatives to the da Vinci system, and robotic endoscope holders. The da Vinci surgical system was the most common robotic assistant $(n=11)$. Overall, the most studies were published in $2017(\mathrm{n}=4)$; no studies published in 2018 or 2019 met inclusion criteria.

\section{Transoral Robotic Surgery}

A total of 4 studies used the da Vinci system with a transoral approach to access the sella turcica and the skull base (Table 1). ${ }^{12-15}$ Two studies had a cadaveric component, serving as an initial proof-of-concept and feasibility study to determine the ability of TORS to access the sella turcica. ${ }^{14,15}$ In all cases, a TORS approach permitted access to the sella, allowing for manipulation of the pituitary gland and optic chiasm. Authors described improved visualization and depth perception using a robotic approach compared with a traditional EEA. In addition, use of the EndoWrist (Intuitive Surgical Inc.) technology mimics human motion and closely resembles traditional surgical gestures. As a result, the TORS approach allowed for improved manipulation and permitted a watertight dural seal using a traditional suturing technique typically not afforded during a nonrobotic EEA.

One study by Carrau et al. investigated the use of a combined TORS approach and EEA to highlight the strengths of each modality. ${ }^{12}$ In their case series of 2 patients, the authors reported that for tumors that extended past the craniocervical junction (e.g., chordoma extending to the level of C1-2), an EEA was used to access tumor to the level of $\mathrm{C} 1$. From there, a TORS approach was used to complete the resection at the level of C2 (Table 2).

In the only clinical trial exclusively using TORS to access the skull base, Chauvet et al. described their experience using TORS for the resection of 4 cystic sellar masses (Fig. 2). ${ }^{13}$ The robotic system was inserted through the patient's mouth, and the sella was approached in an inferosuperior plane; no sublabial incisions were made. The sphenoid sinus was drilled using a traditional endoscopic technique (nonrobotic), following which robotic assistance was again used. In all 4 cases, the authors successfully resected the sellar mass with resultant improvement in preoperative visual symptoms. In this small case 


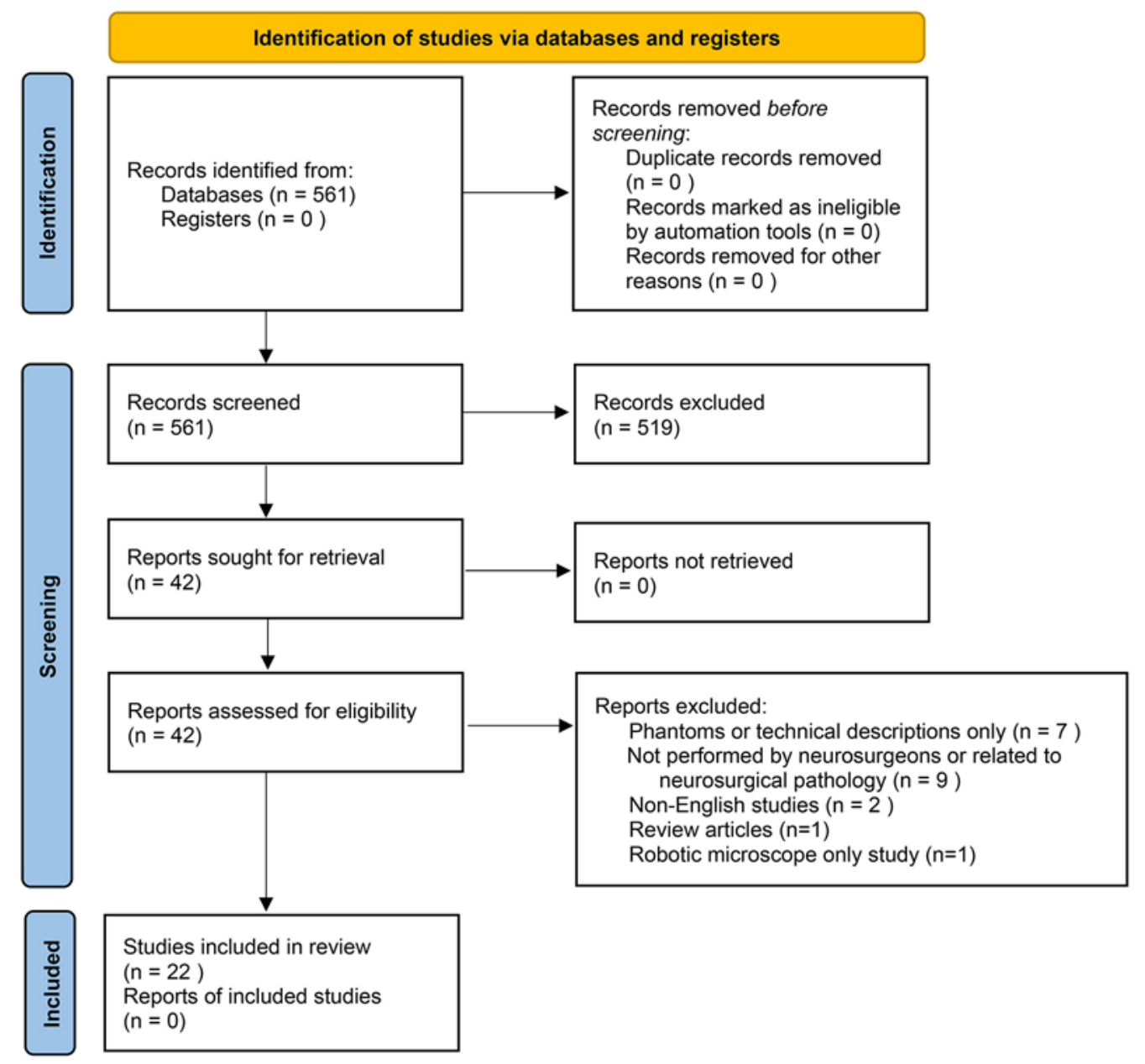

From: Page MJ, McKenzie JE, Bossuyt PM, Boutron I, Hoffmann TC, Mulrow CD, et al. The PRISMA 2020 statement: an updated guideline for reporting systematic reviews. BMJ 2021;372:n71. doi: 10.1136/bmj.n71

For more information, visit: http://www.prisma-statement.org/

FIG. 1. PRISMA flowchart demonstrating the number of included and excluded articles.

series, there was $1 \mathrm{CSF}$ leak and 1 case of diabetes insipidus. TORS-specific side effects included hypernasal speech (3/4 patients), mild sore throat (4/4 patients), and slight nasal obstruction (1/4 patients). There were no episodes of epistaxis or temporomandibular joint pain. Finally, there were no cases of permanent hypopituitarism. The authors commented that the robotic approach avoided the postoperative nasal packing and discomfort typically associated with EEA. The TORS approach also afforded increased stability of the camera compared with a mobile endoscope; finally, the inferosuperior approach to the sella could potentially allow for increased ability to resect tumors with significant suprasellar extension.

There were several limitations of TORS that were consistently emphasized among the reviewed studies. Due to the lack of drilling capabilities with the robotic system, all drilling was done manually via a traditional endoscopic technique; no TORS application facilitated complete robotic surgery with bony removal. In addition, due to the da Vinci system being developed for nonneurosurgical pro- cedures, the size of the instruments was significantly larger than those used during the traditional EEA. For TORS, patients must also have a normal aperture of the mouth, and preoperative CT may be required to identify an appropriate trajectory for the robotic system. The lack of haptic feedback was also described as a significant limitation to the robotic technique, although not specific to TORS.

\section{Alternative Approaches to the Skull Base With the da Vinci System}

Seven studies examined the da Vinci robot (or Raven research robot, compatible with da Vinci tools) in alternative surgical approaches to TORS to access pathology in the skull base and sellar regions (Table 1). ${ }^{16-21}$ All 7 studies were performed in cadavers. The most common da Vinci port placement approaches were via the bilateral maxillary sinuses ( 3 cadaver studies). ${ }^{16,17,22}$ For this approach, the optical port was placed in the nasal cavity and the two surgical arm ports were placed in the antrum of the maxillary 
TABLE 1. Cadaveric studies of robot-assisted systems used for skull base neurosurgery included in the current review

\begin{tabular}{|c|c|c|c|c|}
\hline $\begin{array}{l}\text { Category } \\
\text { (company) }\end{array}$ & $\begin{array}{l}\text { No. of } \\
\text { Cadaveric } \\
\text { Studies }\end{array}$ & $\begin{array}{l}\text { Port } \\
\text { Entry Site }\end{array}$ & $\begin{array}{l}\text { Primary } \\
\text { Anatomic } \\
\text { Exposure }\end{array}$ & Summary of Findings \\
\hline TORS 14,15 & 2 & Oral cavity $(\mathrm{SI}, \mathrm{OA})$ & Sellar region & $\begin{array}{l}\text { Sella approached inferosuperiorly; improved view of surgi- } \\
\text { cal field \& free movement compared w/ EEA; all drilling } \\
\text { done manually }\end{array}$ \\
\hline $\begin{array}{l}\text { Alternative approaches to } \\
\text { TORS }\end{array}$ & 5 & & & \\
\hline Transmaxillary ${ }^{16,17,22}$ & 3 & $\begin{array}{l}\text { Maxillary sinus (SI) (sublabial } \\
\text { incision); nasal corridor } \\
\text { (OA) }\end{array}$ & Sellar region & $\begin{array}{l}\text { Excellent visualization of sella, clivus, \& suprasellar } \\
\text { space; 2-handed, tremor-free closure of dural defects } \\
\text { w/ suture }\end{array}$ \\
\hline Transnasal|18 & 1 & $\begin{array}{l}\text { Expanded nasal corridor (SI, } \\
\text { OA); transmaxillary (SI) }\end{array}$ & Sellar region & $\begin{array}{l}\text { Required significant enlargement of the nasal corridor to } \\
\text { accommodate } 1 \text { surgical instrument \& camera; suturing } \\
\text { of pedicle septal flap was feasible }\end{array}$ \\
\hline Supraorbital ${ }^{19}$ & 1 & $\begin{array}{l}\text { Supraorbital craniotomy (SI, } \\
\text { OA) }\end{array}$ & M1 (MCA) & $\begin{array}{l}\text { Superior visualization of deep-seated structures; ability } \\
\text { to place stitches in vessel w/ relative ease \& speed } \\
\text { compared w/ traditional microsurgery }\end{array}$ \\
\hline Transorbital ${ }^{20}$ & 1 & $\begin{array}{l}\text { Bilateral medial orbits }(\mathrm{SI}) ; \\
\text { nasal corridor }(\mathrm{OA})\end{array}$ & Sellar region & $\begin{array}{l}\text { Major benefit includes restoration of natural working } \\
\text { angles for robotic systems }\end{array}$ \\
\hline Transcervical ${ }^{21}$ & 1 & $\begin{array}{l}\text { Transcervical (posterior to } \\
\text { mandibular gland) (SI); } \\
\text { nasal corridor }(\mathrm{OA})\end{array}$ & Sellar region & $\begin{array}{l}\text { Excellent visualization of sella compared w/ transoral } \\
\text { route of camera }\end{array}$ \\
\hline Alternatives to the da Vinci & & Robot Type, Autonomy Level & Anatomic Region & Summary of Findings \\
\hline $\begin{array}{l}\text { Neuroptic T-30 (Polydi- } \\
\text { agnost) }^{23}\end{array}$ & 1 & Drill, semiautonomous & Sphenoid sinus & $\begin{array}{l}\text { Demonstrated autonomous drilling through the face of the } \\
\text { sphenoid using periop imaging }\end{array}$ \\
\hline $\begin{array}{l}\text { Neuromate (Renishaw } \\
\text { plc) }\end{array}$ & 1 & Drill, semiautonomous & $\begin{array}{l}\text { Internal acoustic } \\
\text { canal }\end{array}$ & $\begin{array}{l}\text { Neuronavigation-based drilling around the internal acous- } \\
\text { tic canal to simulate vestibular schwannoma resection }\end{array}$ \\
\hline $\begin{array}{l}\text { The Flex System } \\
\text { (Medrobotics, now } \\
\text { Brainlab) }^{25}\end{array}$ & 1 & $\begin{array}{l}\text { Flexible endoscope, } \\
\text { surgeon-controlled }\end{array}$ & Sellar region & $\begin{array}{l}\text { Flexible endoscope that allows for greater maneuver- } \\
\text { ability; modified midfacial degloving needed for access; } \\
\text { haptic feedback preserved }\end{array}$ \\
\hline $\begin{array}{l}\text { Versius (CMR Surgi- } \\
\text { cal) }\end{array}$ & 1 & $\begin{array}{l}\text { Robotic system, surgeon- } \\
\text { controlled }\end{array}$ & Sellar region & $\begin{array}{l}\text { Transorbital (OA) \& transnasal (SI) approach; only system } \\
\text { where both robotic arms are placed through nares }\end{array}$ \\
\hline $\begin{array}{l}\text { Prototype by Chumnan- } \\
\text { vej et al., } 2021^{27}\end{array}$ & 1 & $\begin{array}{l}\text { Trajectory guidance, semiau- } \\
\text { tonomous }\end{array}$ & Sphenoid sinus & $\begin{array}{l}\text { Automatically guides surgical instruments to the sphenoid } \\
\text { sinus; uses a QR code tracking system }\end{array}$ \\
\hline
\end{tabular}

$\mathrm{MCA}=$ middle cerebral artery; $\mathrm{OA}=$ optical apparatus (endoscope); $\mathrm{SI}$ = surgical instruments.

sinuses. Given the placement of the optical apparatus, the visualization of sellar anatomy, including the cribriform plate, fovea, planum sphenoidale, clivus, sella, and suprasellar space were all excellent. Kupferman et al. performed a dural incision with robotic scissors and a pituitary gland ex- cision; they commented that the most significant advantage of the robotic system was the ability to perform two-handed dissection with increased dexterity and degrees of freedom given the robotic wristed instruments. The same group performed a skull base reconstruction using the same robotic

TABLE 2. Clinical studies using robot-assisted systems for skull base neurosurgery

\begin{tabular}{|c|c|c|c|c|}
\hline Authors \& Year & Objective & System & Study Design (n) & Key Findings \\
\hline $\begin{array}{l}\text { Carrau et al., } \\
2013^{12}\end{array}$ & $\begin{array}{l}\text { EEA \& TORS } \\
\text { combination } \\
\text { cases }\end{array}$ & da Vinci & $\begin{array}{l}\text { Cadaveric (2), clin- } \\
\quad \text { ical study (2) }\end{array}$ & $\begin{array}{l}\text { Demonstrated feasibility of combined EEA \& TORS; in } 2 \text { pts, adenoid cystic carci- } \\
\text { noma extending into the sphenoid sinus \& clivus, \& chordoma extending from the } \\
\text { posterior/middle skull base to the C2 level; TORS approach for inferior aspects \& } \\
\text { EEA for superior aspects of tumor resulted in favorable op outcomes }\end{array}$ \\
\hline $\begin{array}{l}\text { Chauvet et al., } \\
2017^{13}\end{array}$ & $\begin{array}{c}\text { Exclusive } \\
\text { TORS }\end{array}$ & da Vinci & Clinical study (4) & $\begin{array}{l}4 \text { pts w/ mostly cystic sellar pathologies removed via TORS only; sphenoid sinus } \\
\text { was opened via a nonrobotic technique; vision improvement in 4/4 pts; complica- } \\
\text { tions included CSF leakage (1 pt) \& DI (1 pt) }\end{array}$ \\
\hline
\end{tabular}

$\mathrm{DI}=$ diabetes insipidus; $\mathrm{pt}=$ patient 


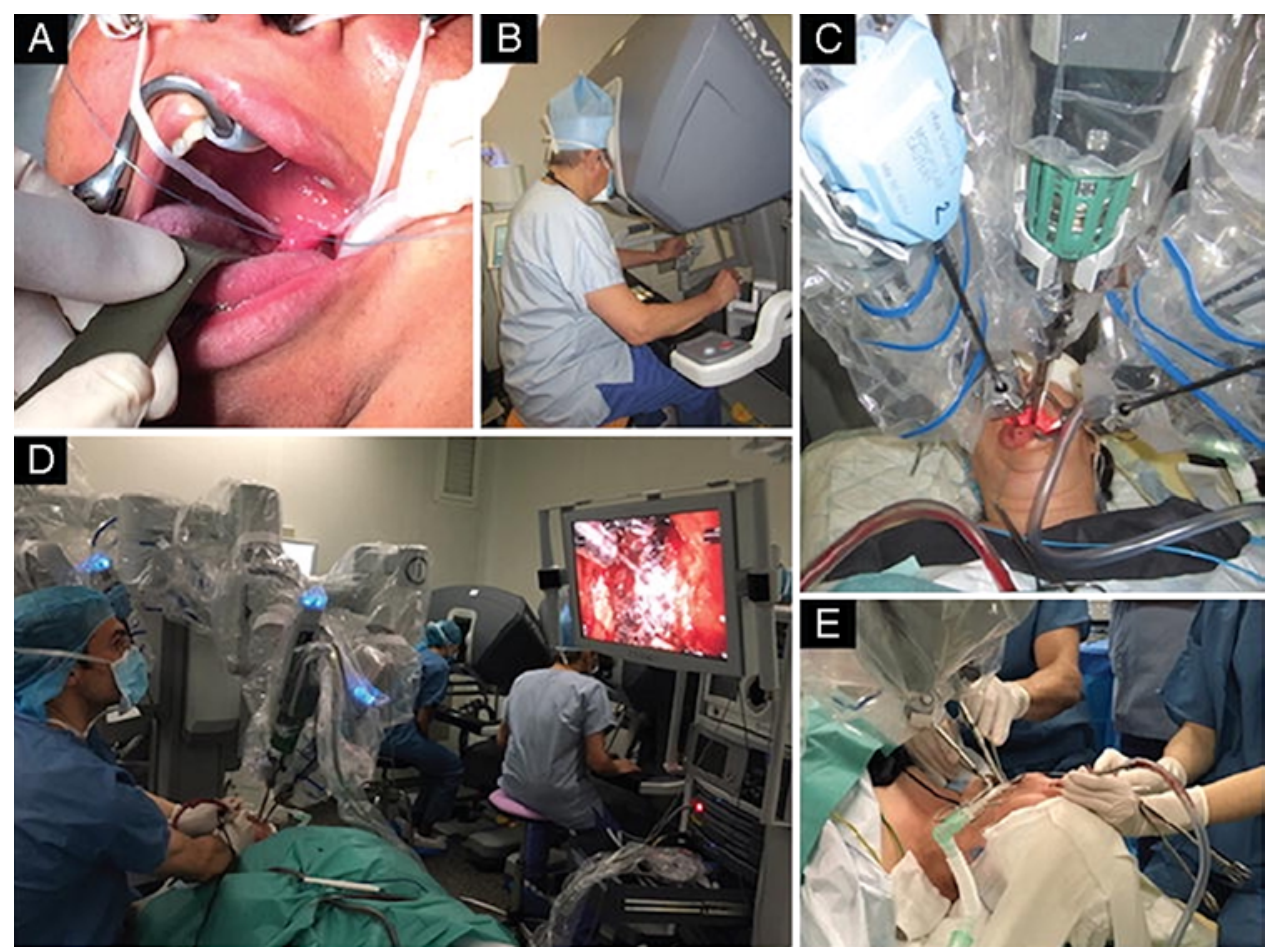

FIG. 2. Photographs showing a sample operative setup for the TORS approach to sellar lesions. A: Mouth exposure. B: Mucosal dissection being performed at the console of the robot. C: Mucosal phase. D and E: Sphenoidal phase. Reprinted from Chauvet D, Hans S, Missistrano A, Rebours C, Bakkouri WE, Lot G. Transoral robotic surgery for sellar tumors: first clinical study. J Neurosurg. 2017;127(4):941-948. ${ }^{13}$ Published with permission.

approach and reported successful creation of a primary dural closure using sutures and a mucoperiosteal graft. ${ }^{16,17}$

While the transmaxillary approach was the most well studied, multiple other port access points were used, including a transcervical route in which surgical arm ports were inserted behind the submandibular gland, a transorbital route where arm ports were inserted in bilateral medial orbits, and a completely transnasal route using an expanded nasal corridor. ${ }^{18-21}$ In addition, a supraorbital keyhole approach was used and the da Vinci system was tested for suturing a portion of the M1 segment of the middle cerebral artery in a cadaveric model. ${ }^{19}$

\section{Alternatives to the da Vinci Robot}

There were 5 alternative robotic assistants to the da Vinci identified in this study (Table 1). Two systems were designed to assist in bone drilling; one through the face of the sphenoid sinus and the other around the internal auditory canal to simulate vestibular schwannoma resection. ${ }^{23,24}$ The remaining 3 studies all attempted to address the size of the robotic system needed for skull base neurosurgery. The Flex System (Medrobotics) tested the feasibility of a single-port robotic system in which flexible robotic arms were attached to the side of the endoscope and controlled at the bedside..$^{25}$ This required a modified midfacial degloving technique and partial resection of the nasal septum but provided haptic feedback and excellent visualization of the pituitary fossa and optic chiasm and enabled complete skull base removal and visualization of the posterior cranial fossa and frontal lobe.
The Versius system (CMR Surgical) was similarly designed to have a small surgical footprint and modular design specific for microsurgical approaches. For this system, a bilateral transorbital approach for the surgical ports and a transnasal approach for the endoscope was used. ${ }^{26}$ Finally, Chumnanvej et al. developed their own custom prototype for a robotic EEA and used preoperative imaging, a QR code-based tracking technology, and intraoperative fluoroscopy for semiautomatic (neurosurgeonsupervised) robotic guidance of a surgical tool to reach the base of the sphenoid sinus. ${ }^{27}$ The authors reported a robotic time-to-task completion of $<30$ minutes for robotic setup and docking and $<2$ minutes to task completion (reaching the sphenoid sinus).

\section{Robotic Endoscope Holders}

Robotic endoscope holders were reported in 6 studies, of which 3 were clinical studies composed of a total of 75 patients (Table 3). ${ }^{28-33}$ The iArmS (DENSO Corp.) operation-support robot is an electromagnetic surgeon support tool that allows a neurosurgeon to rest their forearms while operating, thus, reducing fatigue and increasing stability (Fig. 3). It was used in 43 patients with favorable perceived effects on performance, and was easy to use and maneuver. ${ }^{32}$ The ENDOFIX exo system (AKTORmed) is a robotic endoscope holder that was used in a clinical trial of 30 patients, 11 of whom underwent transsphenoidal resection of a pituitary adenoma. The endoscope holder could be mobilized and locked with 6 different degrees of freedom by the surgeon..$^{33}$ It has a fixed clamp, which 
TABLE 3. Studies using robotic endoscope holders or assistants for skull base neurosurgery

\begin{tabular}{|c|c|c|c|}
\hline Robotic System & Style & Study Design (n) & Key Findings \\
\hline $\begin{array}{l}\text { Evolution } 1 \text { (Universal } \\
\text { Robotic Systems) }{ }^{28}\end{array}$ & $\begin{array}{l}\text { Endoscope } \\
\text { holder }\end{array}$ & Clinical trial (2) & $\begin{array}{l}\text { Advantage of modular design \& disadvantage of cumbersome prepositioning; only } \\
\text { used as an endoscope holder for microsurgical resection (no EEA) }\end{array}$ \\
\hline $\begin{array}{l}\text { Stewart Platform (Kocaeli } \\
\text { University) })^{29}\end{array}$ & $\begin{array}{l}\text { Endoscope } \\
\text { holder }\end{array}$ & Cadaveric & $\begin{array}{l}\text { Joystick-based endoscope holder \& robot; ease of use for surgeon, large design is dif- } \\
\text { ficult to place, requires other surgical staff; allows for slow, smooth motions; would } \\
\text { only be used following transsphenoidal portion of EEA }\end{array}$ \\
\hline $\begin{array}{l}\text { Brescia Endoscope As- } \\
\text { sistant Robotic Holder }{ }^{30}\end{array}$ & $\begin{array}{l}\text { Endoscope } \\
\text { holder }\end{array}$ & Cadaveric & $\begin{array}{l}\text { Robotic endoscope holder controlled by surgeon via combination of interactive } \\
\text { glasses, Microsoft Kinect technology, \& voice activation; purpose was to design } \\
\text { a holder for portions of surgery w/ minimal camera movement; emergency "stop" } \\
\text { functions \& force sensors to minimize risk of injury }\end{array}$ \\
\hline $\begin{array}{l}\text { Medineering (now Brain- } \\
\text { lab AG) }\end{array}$ & $\begin{array}{l}\text { Endoscope } \\
\text { holder }\end{array}$ & Cadaveric & $\begin{array}{l}\text { Robotic endoscope guidance system controlled by surgeon w/ joystick; can easily be } \\
\text { attached to the standard side rails of a surgical table; currently needs an additional } \\
\text { surgeon or assistant to clean \& irrigate }\end{array}$ \\
\hline iArmS (DENSO Corp.) ${ }^{32}$ & $\begin{array}{l}\text { Robotic } \\
\text { armrest }\end{array}$ & Clinical trial (43) & $\begin{array}{l}\text { Robotic intraop armrests; locks \& moves freely w/o buttons or complex adjustments; } \\
\text { decreases fatigue, reduces hand trembling, \& improves surgeon comfort }\end{array}$ \\
\hline $\begin{array}{l}\text { ENDOFIX exo } \\
\text { (AKTORmed) }^{33}\end{array}$ & $\begin{array}{l}\text { Endoscope } \\
\text { holder }\end{array}$ & Clinical study (30) & $\begin{array}{l}\text { Electromagnetic manual support arm to hold the endoscope; push-\&-hold feature } \\
\text { releases the scope \& allows it to be moved \& locked again; used in } 30 \text { pts, } 11 \text { pts w/ } \\
\text { transsphenoidal resection of PAs; fixed clamp, easy to sterilize, \& low cost }\end{array}$ \\
\hline
\end{tabular}

PA = pituitary adenoma

There were 3 clinical applications totaling 75 patients.

can be easily docked onto an operating room table, and is low cost and easy to sterilize. Maneuvering the endoscope requires the surgeon to remove tools from the field of view, however, and, given its fixed positioning, may increase the risk of injury if there is movement of the patient. Other endoscope holder designs were tested in cadavers. These designs varied widely and included the use of foot pedals or joysticks for scope movement, interactive glasses, a Microsoft Kinect motion sensing system, and voice control. ${ }^{29-31}$

\section{Discussion}

The proportion of surgical procedures using robot-as-

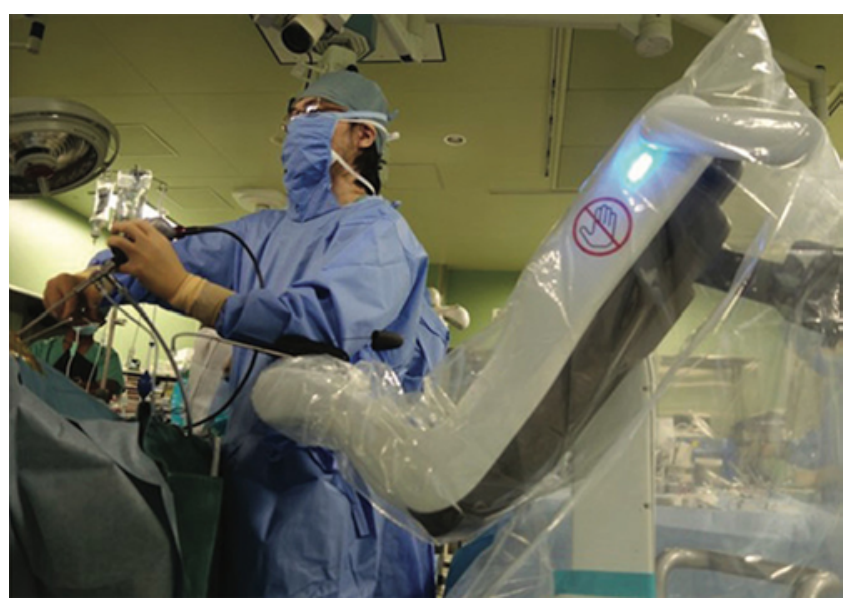

FIG. 3. Sample operative setup for the iArmS robotic armrest support system. Reprinted from Ogiwara T, Goto T, Nagm A, Hongo K. Endoscopic endonasal transsphenoidal surgery using the iArmS operation support robot: initial experience in 43 patients. Neurosurg Focus. 2017;42(5):E10. ${ }^{32}$ Published with permission. sisted systems is growing rapidly, with a variety of semicustomizable robotic systems currently available on the market. ${ }^{10,34}$ There have been promising attempts at incorporating robotic instrumentation into skull base neurosurgery, although the overall impact and scope of robotics in the daily practice of skull base neurosurgery is minimal. We performed this review to identify current strategies and attempts for accessing skull base anatomy using robotics and to identify potential systems or approaches that may have feasibility over the coming years. In addition, we identify the benefits and limitations to current-generation robotic systems for skull base neurosurgery and discuss important features, from a neurosurgical perspective, that should be prioritized by the next generation of robotic system developers.

\section{Benefits and Current Limitations of Robotic Assistants}

The da Vinci system and other surgeon-controlled consoles have advantages that would make them potentially applicable to skull base neurosurgery. First, they allow for gesture-based movements that mimic traditional surgical technique (e.g., allowing multiple degrees of freedom). This maneuverability in tight spaces has allowed for the use of a suture to reconstruct dural defects in multiple studies, and participants felt this was a significant advantage over current endoscopic techniques. ${ }^{16,18} \mathrm{CSF}$ leakage remains one of the most common complications of endonasal surgery, ${ }^{1,35,36}$ and the ability to create better watertight seals may be an improvement over current techniques. Robotic systems today also offer tremor filtration and instrument position memory. In abdominal surgeries, wide working windows and relative maneuverability around the abdomen make these features useful but perhaps less integral. If implemented successfully, the narrow operative corridors and delicate surrounding anatomy in neurosurgical procedures would make these features particularly valuable. 
Despite the theoretical advantages, current robotic systems have significant limitations that likely hinder their ability to be applied systematically across skull base procedures. The overall port size of robotic platforms remains too large for most neurosurgical skull base operations, particularly those performed via natural corridors or minimally invasive keyhole approaches. Similarly, instruments designed for abdominal surgery remain too large to be applied in a minimally invasive fashion for most skull base cases. The TORS approach has been safe and efficacious for otorhinolaryngological procedures $;{ }^{10}$ however, the ability of this approach to be applied to skull base surgery is likely limited to the sella and parasellar areas, given the anatomical constraints of a transoral access point and constraints associated with a trajectory aimed cranially toward the skull base. In addition, the sole clinical series using TORS was performed on mostly cystic lesions contained within the sella and suprasellar space; it is yet to be seen how the TORS approach can be applied to tumors invading the cavernous sinus or those that may require significant two-handed microdissection to resect. Management of surgical complications such as vascular injury with robotic platforms may also carry new and unforeseen challenges that have yet to be encountered or explored. Other surgical approaches currently are not feasible for skull base neurosurgery and require significant cosmetic deformation in order to achieve optimal operating angles between surgical arms (e.g., midfacial devolving and transorbital approaches). ${ }^{18,20}$ Smaller instruments may overcome these current limitations. Particularly given the safety and efficacy of endoscopic endonasa ${ }^{2,3,37}$ and microsurgical procedures to access the skull base, the risk-benefit analysis of using a robotic approach at this time remains unfavorable. The lack of drilling tools remains another significant limitation, as robotic surgical workflows must be interrupted to manually drill, or to set up the robot following drilling.

Finally, the large startup costs (for hospitals) and usage costs (for patients) is another concerning factor that likely limits the current generation of robotic systems from being more widely applied. While outside the scope of the current review, robotic surgery has been shown in other disciplines to cost a hospital 1.4 to 2 times as much as the same, nonrobotic procedures. ${ }^{38,39}$ However, the ability to perform neurosurgical procedures using these tools may offset the cost burden on hospitals that already have a robotic system set up.

\section{Robotic Instrument Holders}

Robotic instrument holders, or systems that simply make operating "easier," may allow for more immediate usage compared with fully robotic assistants (e.g., the da Vinci). Robotic instrument holders or operative support systems have seen use in clinical studies, and generally reduce operator fatigue, allow for concentration on more meaningful tasks, and permit a two-handed operative setup without a surgical assistant. The systems can also aid in cleaning the lens and ensuring standardized and stable views, which has already been demonstrated in nonneurosurgical endoscopic cases. ${ }^{40}$ Ultimately, these tools may improve operating room workflow, minimize distraction, and reduce operative time. They are also likely to cost less than fully robotic assistants, carry less risk, and be reviewed favorably by surgeons if they perform with adequate reliability.

\section{Future Directions}

It is worth noting that in this review, the only clinical series using a fully robotic surgical system (e.g., the da Vinci) was published in 2017 and there were no studies published in 2018 or 2019 and only 1 that was published in 2020 fit our inclusion criteria. It is possible that the effects of COVID-19 have prevented substantial claims about interest in robotic technology for skull base surgery; none the less, it may be a relatively understudied area of interest given its potential for improved surgical safety and patient outcomes.

The primary challenges to overcome are technical and physical in nature. Robotic instruments must be miniaturized to be useful in true skull base neurosurgery, which mandates two-handed microdissection and haptic feedback. In addition, current nasal endoscopes are $<4 \mathrm{~mm}$ in size, compared with standard da Vinci endoscopes, which are $12 \mathrm{~mm} .{ }^{41}$ Skull base pathology is often deep and only accessible through narrow corridors. Current surgical assistants require an operative angle of $90^{\circ}$ between surgical arms, which is rarely, if ever, feasible in skull base cases. Future-generation surgical assistants should also be stable enough and powerful enough to permit drilling through bone. Multiport robotic systems that focus on miniaturization and maximizing surgical freedom may be a future avenue for application of robotic technology in neurological skull base surgery. It is worth mentioning that the current studies do not employ the latest da Vinci model, which uses a single-port system..$^{42}$ The TORS approach is likely the most feasible approach using a single-port system compared with other approaches that require multiple sites of entry.

Finally, the use of surgical systems allows for significant integration and usage of artificial intelligence and the growing field of surgical data science. Groups in other disciplines have used instrument position and event data taken from robotic systems (termed automated performance metrics) to correlate surgeon performance with clinical outcomes. ${ }^{43-45}$ Additionally, significant work is being conducted to automatically detect surgical anatomy and instruments using machine learning and/or computer vision techniques. These approaches could have potential utility in robotic systems if they can assist in automatic camera focus, augment force application, or provide support in complication management. ${ }^{46,47}$ Lastly, current limitations with many augmented realities and neuronavigation setups include inaccuracy and interruption of workflow, which an integrated robotic setup may aid in alleviating.

\section{Limitations}

There are multiple limitations to the current study. The most significant limitation is publication lag. Given the inherent delays in carrying out studies of innovative technology, especially clinical studies, review articles are, by definition, outdated from current work and likely do not represent the latest technological advancements. In addition, given the need for industry investment in robotic 
technologies, advancements that are outside the scope of academic literature may exist. Our work is also limited by the inherent limitations of systematic reviews, namely, publication bias, variable experimental design and results reporting, and potential biases or industry influence central to the articles that were analyzed.

\section{Conclusions}

Robotic applications to skull base neurosurgery may allow for greater visualization, maneuverability, and decreased user fatigue. Clinical applications of robot-assisted systems for skull base procedures exist, although significant limitations restrict their applicability. The next generation of robotic assistants for skull base neurosurgery should prioritize decreased size, more flexible operating angles, and the ability to remove bony elements.

\section{References}

1. Zada G, Kelly DF, Cohan P, Wang C, Swerdloff R. Endonasal transsphenoidal approach for pituitary adenomas and other sellar lesions: an assessment of efficacy, safety, and patient impressions. J Neurosurg. 2003;98(2):350-358.

2. Cardinal T, Brunswick A, Strickland BA, et al. Safety and effectiveness of the direct endoscopic endonasal approach for primary sellar pathology: a contemporary case series of more than 400 patients. World Neurosurg. 2021;148:e536-e546.

3. Dallapiazza RF, Grober Y, Starke RM, Laws ER Jr, Jane JA Jr. Long-term results of endonasal endoscopic transsphenoidal resection of nonfunctioning pituitary macroadenomas. Neurosurgery. 2015;76(1):42-53.

4. Younus I, Gerges MM, Uribe-Cardenas R, et al. How long is the tail end of the learning curve? Results from 1000 consecutive endoscopic endonasal skull base cases following the initial 200 cases. J Neurosurg. 2020;134(3):750-760.

5. Leach P, Abou-Zeid AH, Kearney T, Davis J, Trainer PJ, Gnanalingham KK. Endoscopic transsphenoidal pituitary surgery: evidence of an operative learning curve. Neurosurgery. 2010;67(5):1205-1212.

6. Amelot A, Trunet S, Degos V, et al. Anatomical features of skull base and oral cavity: a pilot study to determine the accessibility of the sella by transoral robotic-assisted surgery. Neurosurg Rev. 2015;38(4):723-730.

7. Ball T, González-Martínez J, Zemmar A, et al. Robotic applications in cranial neurosurgery: current and future. Oper Neurosurg (Hagerstown). 2021;21(6):371-379.

8. Lim JY, Park YM, Kang MS, et al. Comparison of surgical outcomes of robotic and conventional approaches in patients with pre- and poststyloid parapharyngeal space tumors. Ann Surg Oncol. 2020;27(11):4535-4543.

9. De Virgilio A, Costantino A, Mercante G, Di Maio P, Iocca O, Spriano G. Trans-oral robotic surgery in the management of parapharyngeal space tumors: a systematic review. Oral Oncol. 2020;103:104581.

10. Boehm F, Graesslin R, Theodoraki MN, et al. Current advances in robotics for head and neck surgery-a systematic review. Cancers (Basel). 2021;13(6):1398.

11. Moher D, Liberati A, Tetzlaff J, Altman DG. Preferred reporting items for systematic reviews and meta-analyses: the PRISMA statement. BMJ. 2009;339:b2535.

12. Carrau RL, Prevedello DM, de Lara D, Durmus K, Ozer E. Combined transoral robotic surgery and endoscopic endonasal approach for the resection of extensive malignancies of the skull base. Head Neck. 2013;35(11):E351-E358.

13. Chauvet D, Hans S, Missistrano A, Rebours C, Bakkouri WE, Lot G. Transoral robotic surgery for sellar tumors: first clinical study. J Neurosurg. 2017;127(4):941-948.
14. Chauvet D, Missistrano A, Hivelin M, Carpentier A, Cornu $\mathrm{P}$, Hans S. Transoral robotic-assisted skull base surgery to approach the sella turcica: cadaveric study. Neurosurg Rev. 2014;37(4):609-617.

15. Fernandez-Nogueras FJJ, Katati MJ, Arraez Sanchez MA, Molina Martinez M, Sanchez Carrion M. Transoral robotic surgery of the central skull base: preclinical investigations. Eur Arch Otorhinolaryngol. 2014;271(6):1759-1763.

16. Kupferman ME, Demonte F, Levine N, Hanna E. Feasibility of a robotic surgical approach to reconstruct the skull base. Skull Base. 2011;21(2):79-82.

17. Kupferman M, Demonte F, Holsinger FC, Hanna E. Transantral robotic access to the pituitary gland. Otolaryngol Head Neck Surg. 2009;141(3):413-415.

18. Blanco RGF, Boahene K. Robotic-assisted skull base surgery: preclinical study. J Laparoendosc Adv Surg Tech A. 2013; 23(9):776-782.

19. Hong WC, Tsai JC, Chang SD, Sorger JM. Robotic skull base surgery via supraorbital keyhole approach: a cadaveric study. Neurosurgery. 2013;72(suppl 1):33-38.

20. Bly RA, Su D, Lendvay TS, et al. Multiportal robotic access to the anterior cranial fossa: a surgical and engineering feasibility study. Otolaryngol Head Neck Surg. 2013;149(6): 940-946.

21. Dallan I, Castelnuovo P, Seccia V, et al. Combined transnasal transcervical robotic dissection of posterior skull base: feasibility in a cadaveric model. Rhinology. 2012;50(2):165-170.

22. Hanna EY, Holsinger C, DeMonte F, Kupferman M. Robotic endoscopic surgery of the skull base: a novel surgical approach. Arch Otolaryngol Head Neck Surg. 2007;133(12): 1209-1214.

23. Bumm K, Wurm J, Rachinger J, et al. An automated robotic approach with redundant navigation for minimal invasive extended transsphenoidal skull base surgery. Minim Invasive Neurosurg. 2005;48(3):159-164.

24. Kazanzides P, Xia T, Baird C, et al. A cooperatively-controlled image guided robot system for skull base surgery. Stud Health Technol Inform. 2008;132:198-203.

25. Schuler PJ, Scheithauer M, Rotter N, Veit J, Duvvuri U, Hoffmann TK. A single-port operator-controlled flexible endoscope system for endoscopic skull base surgery. HNO. 2015;63(3):189-194.

26. Faulkner J, Naidoo R, Arora A, Jeannon JP, Hopkins C, Surda P. Combined robotic transorbital and transnasal approach to the nasopharynx and anterior skull base: feasibility study. Clin Otolaryngol. 2020;45(4):630-633.

27. Chumnanvej S, Pillai BM, Chalongwongse S, Suthakorn J. Endonasal endoscopic transsphenoidal approach robot prototype: a cadaveric trial. Asian J Surg. 2021;44(1):345-351.

28. Nimsky Ch, Rachinger J, Iro H, Fahlbusch R. Adaptation of a hexapod-based robotic system for extended endoscopeassisted transsphenoidal skull base surgery. Minim Invasive Neurosurg. 2004;47(1):41-46.

29. Cabuk B, Ceylan S, Anik I, Tugasaygi M, Kizir S. A haptic guided robotic system for endoscope positioning and holding. Turk Neurosurg. 2015;25(4):601-607.

30. Bolzoni Villaret A, Doglietto F, Carobbio A, et al. Robotic transnasal endoscopic skull base surgery: systematic review of the literature and report of a novel prototype for a hybrid system (Brescia Endoscope Assistant Robotic Holder). World Neurosurg. 2017;105:875-883.

31. Friedrich DT, Sommer F, Scheithauer MO, Greve J, Hoffmann TK, Schuler PJ. An innovate robotic endoscope guidance system for transnasal sinus and skull base surgery: proof of concept. J Neurol Surg B Skull Base. 2017;78(6): 466-472.

32. Ogiwara T, Goto T, Nagm A, Hongo K. Endoscopic endonasal transsphenoidal surgery using the iArmS operation support robot: initial experience in 43 patients. Neurosurg Focus. 2017;42(5):E10. 
33. Hintschich CA, Fischer R, Seebauer C, Schebesch KM, Bohr C, Kühnel T. A third hand to the surgeon: the use of an endoscope holding arm in endonasal sinus surgery and well beyond. Eur Arch Otorhinolaryngol. Published online June 20, 2021. doi:10.1007/s00405-021-06935-x

34. Hajirawala LN, Leonardi C, Orangio GR, Davis KG, Barton JS. Trends in open, laparoscopic, and robotic approaches to colorectal operations. Am Surg. Published online July 28, 2021. doi:10.1177/00031348211034754

35. Agam MS, Wedemeyer MA, Wrobel B, Weiss MH, Carmichael JD, Zada G. Complications associated with microscopic and endoscopic transsphenoidal pituitary surgery: experience of 1153 consecutive cases treated at a single tertiary care pituitary center. J Neurosurg. 2019;130(5):1576-1583.

36. Hardesty DA, Montaser A, Kreatsoulas D, et al. Complications after 1002 endoscopic endonasal approach procedures at a single center: lessons learned, 2010-2018. J Neurosurg. Published online August 6, 2021. doi:10.3171/2020.11. JNS202494

37. Zhu H, Li C, Gui S, et al. Experience of endoscopic endonasal approach for 803 pituitary tumors with cavernous sinus invasion. J Craniofac Surg. Published online July 29, 2021. doi:10.1097/SCS.0000000000008049

38. Quilici PJ, Wolberg H, McConnell N. Operating costs, fiscal impact, value analysis and guidance for the routine use of robotic technology in abdominal surgical procedures. Surg Endosc. Published online April 9, 2021. doi:10.1007/s00464021-08428-8

39. Alshowaikh K, Karpinska-Leydier K, Amirthalingam J, et al. Surgical and patient outcomes of robotic versus conventional laparoscopic hysterectomy: a systematic review. Cureus. 2021;13(8):e16828.

40. Okuda H, Okamoto J, Takumi Y, Kakehata S, Muragaki Y. The iArmS robotic armrest prolongs endoscope lens-wiping intervals in endoscopic sinus surgery. Surg Innov. 2020;27(5): 515-522.

41. KARL STORZ Endoskope. Otorhinolaryngology. Accessed November 16, 2021. https://www.karlstorz.com/us/en/earnose-throat.htm

42. Intuitive Surgical. da Vinci SP. Accessed November 16, 2021. https://www.intuitive.com/en-us/products-and-services/davinci/systems/sp
43. Hung AJ, Chen J, Gill IS. Automated performance metrics and machine learning algorithms to measure surgeon performance and anticipate clinical outcomes in robotic surgery. JAMA Surg. 2018;153(8):770-771.

44. Hung AJ, Chen J, Ghodoussipour S, et al. A deep-learning model using automated performance metrics and clinical features to predict urinary continence recovery after robotassisted radical prostatectomy. BJU Int. 2019;124(3):487-495.

45. Chen J, Oh PJ, Cheng N, et al. Use of automated performance metrics to measure surgeon performance during robotic vesicourethral anastomosis and methodical development of a training tutorial. J Urol. 2018;200(4):895-902.

46. Ward TM, Mascagni P, Ban Y, et al. Computer vision in surgery. Surgery. 2021;169(5):1253-1256.

47. Staartjes VE, Volokitin A, Regli L, Konukoglu E, Serra C. Machine vision for real-time intraoperative anatomic guidance: a proof-of-concept study in endoscopic pituitary surgery. Oper Neurosurg (Hagerstown). 2021;21(4):242-247.

\section{Disclosures}

The authors report no conflict of interest concerning the materials or methods used in this study or the findings specified in this paper.

\section{Author Contributions}

Conception and design: Zada, Pangal, Cote. Acquisition of data: Pangal, Yarovinsky. Analysis and interpretation of data: Pangal, Cote, Yarovinsky. Drafting the article: Pangal, Cote. Critically revising the article: Pangal, Cote, Ruzevick, Kugener, Wrobel, Ference, Swanson. Reviewed submitted version of manuscript: all authors. Statistical analysis: Pangal. Administrative/technical/ material support: Zada. Study supervision: Zada, Ruzevick.

\section{Correspondence}

Gabriel Zada: Keck School of Medicine of the University of Southern California, Los Angeles, CA. gzada@usc.edu. 